\title{
Estudo e Implementação de um Sistema Customizável para Controle Laboratorial para o Processo de Tipificação HLA
}

\author{
Marcio N. P. Silva ${ }^{1}$, Luís Cristóvão M. S. Pôrto ${ }^{2}$, Leandro A. J. Marzulo ${ }^{1}$, \\ Alexandre C. Sena ${ }^{1}$ \\ ${ }^{1}$ Instituto de Matemática e Estatística \\ Universidade do Estado do Rio de Janeiro (UERJ) \\ ${ }^{2}$ Laboratório de Histocompatibilidade e Criopreservação \\ Universidade do Estado do Rio de Janeiro (UERJ)
}

\{marcionps, luis.cristovaoporto\}@gmail.com, \{asena, leandro\}@ime.uerj.br

\begin{abstract}
A favorable compatibility between donor/recipient considerably reduces the chance of rejection. In humans, the genetic grouping of the DNA responsible for the immune system is called HLA. Laboratory tests were developed to identify this grouping and one of them is HLA typing. These evaluations need to be performed by specialized laboratories and in this context the Laboratory of Histocompatibility and Cryopreservation of the University of the State of Rio de Janeiro (HLA-UERJ) has a prominent position in the sector. The process as a whole is complex and extensive, involving diverse teams and sectors of the laboratory, with an intense exchange of information. Data processing is extremely important and requires strict control to ensure the traceability and reliability of results. In this context, the objective of this work is to presents a detailed study of the HLA typing process and an implementation of a customizable control system for laboratory processes management.
\end{abstract}

Resumo. Uma compatibilidade favorável entre doador/receptor diminui consideravelmente a chance de rejeição em transplantes. Nos humanos o grupamento gênico do DNA responsável pelo sistema imune é denominado HLA. Testes laboratoriais foram desenvolvidos para identificar esse grupamento e um deles é a tipificação HLA. Essas avaliações precisam ser realizadas por laboratórios especializados e nesse contexto o Laboratório de Histocompatibilidade e Criopreservação da Universidade do Estado do Rio de Janeiro (HLA-UERJ) tem posição de destaque no setor. O processo como um todo é complexo e extenso, envolvendo diversas equipes e setores do laboratório, com uma intensa troca de informações. Os dados tratados são extremamente importantes o que demanda um rígido controle para garantir a rastreabilidade e confiabilidade dos resultados. Nesse contexto, o objetivo deste trabalho é mapear todo o processo de tipificação HLA e apresentar e implementar um sistema customizável para gerenciamento de processos laboratoriais.

\section{Introdução}

O sistema imunológico tem um papel fundamental nos transplante de orgãos. Mecanismos complexos de imunidade, que em circunstâncias normais funcionam para identificar 
organismos estranhos e direcionar o sistema imunológico para destruí-los, podem também representar uma barreira significativa para um transplante bem-sucedido. Esse fenômeno é conhecido como rejeição [Abbas and Lichtman 2004].

Estudos mostraram que todas as espécies possuem um grupamento gênico no DNA cuja função está diretamente ligada a resposta imunológica. Essa região foi denominada complexo de histocompatibilidade principal - MHC (do inglês Major Histocompatibility Complex). As proteínas codificadas por certos genes desse grupo exercem uma função importante no controle do reconhecimento de antígenos próprios e antígenos externos. Nos humanos esse grupamento é denominado HLA (do inglês Human Leukocyte Antigen) pelo fato desses antígenos serem expressos nos leucócitos humanos. Embora existam outros fatores não imunológicos que devem ser levados em consideração para realização do transplante, foi comprovado que uma compatibilidade HLA favorável tem um papel significante para diminuir as chances de rejeição [Opelz and Döhler 2007].

Existem testes laboratoriais que tem por intuito identificar a possibilidade de ocorrência desse problema antes do transplante em si ocorrer, e o mais importante deles é a tipificação HLA. Esse teste identifica os antígenos do sangue que poderiam vir a atacar o órgão transplantado. Todas essas avaliações precisam ser realizadas por laboratórios especializados que contam com equipamentos específicos para esse fim. Nesse contexto o laboratório de Histocompatibilidade e Criopreservação da Universidade do Estado do Rio de Janeiro (HLA-UERJ), ocupa uma posição de destaque no setor. O HLA-UERJ, localizado na Policlínica Piquet Carneiro, atua nas áreas de ensino, pesquisa e assistência, realizando exames de imunogenética pertinentes aos transplantes renais e atua como colaborador no cadastramento de doadores voluntários do Registro Nacional de Doadores de Medula Óssea (REDOME) [HLA-UERJ 2018].

Para a realização dos exames, o laboratório aplica técnicas de sequenciamento de DNA e identificação de genótipos do complexo principal de histocompatibilidade humano (HLA). O processo como um todo é bastante complexo, pois envolve diversas etapas, mobiliza diversos equipamentos e equipes alocados em diferentes setores dentro do laboratório. Há uma intensa troca de informações o que demanda um rígido controle para garantir a rastreabilidade e confiabilidade das amostras e dados gerados, e posterior arquivamento dos resultados.

Atualmente, em um típico laboratório de análises clínicas, a maioria do volume processado é realizada por equipamentos automatizados [Campana et al. 2011]. Para integração de todo o sistema laboratorial e facilitar a difusão da informação, é comum a utilização de sistemas informatizados especializados. Esse sistema de gestão laboratorial é conhecido como LIMS (do inglês Laboratory Information Management System) e consiste de um software que serve como um integrador de processos, englobando todo o fluxo de informações, dados dos usuários, informações das amostras, integração com os equipamentos, análise de dados, geração de relatórios, entre outros [Paszko and Turner 2001].

Embora o HLA-UERJ possua equipamentos modulares especialistas bastante avançados, não existe um agente para integrar as informações oriundas dos diversos equipamentos. Assim, este trabalho apresenta um mapeamento completo de todo o processo de tipificação HLA. Além disso, este trabalho apresenta a implementação completa de um sistema de gestão laboratorial (LIMS) para todo o processo de tipificação HLA. Um 
importante destaque é que o sistema desenvolvido é customizável para que não só atenda as necessidades atuais do laboratório, mas que também possa ser expandido com outras funcionalidades de forma prática. Essa abordagem teve o objetivo de deixar a aplicação com o escopo mais amplo, podendo atender outros tipos de laboratórios.

Para o desenvolvimento, optou-se por construir uma aplicação web, ou seja, o usuário irá interagir com a aplicação a partir de um browser (Firefox ou Google Chrome, por exemplo), não necessitando que seja instalado nada nos computadores. A aplicação será toda gerida por um servidor contendo o código e o banco de dados necessário. Outra vantagem dessa abordagem é que com poucos ajustes é possível adaptar todo a aplicação para uso em dispositivos móveis (tablets, por exemplo).

Este trabalho está dividido da seguinte maneira: a metodologia adotada se encontra na Seção 2. Em seguida, a Seção 3 descreve o processo de tipificação HLA e o mapeamento proposto. Por sua vez, a Seção 4 apresenta brevemente a evolução da automação dos processos laboratoriais. O sistema de gerenciamento laboratorial para o processo de tipificação HLA é apresentado na Seção 5. Por fim, as conclusões e os trabalhos futuros são apresentados na Seção 6.

\section{Metodologia}

Um obstáculo inicial que precisava ser transposto é o fato de duas áreas tão distintas estarem criando uma interface comum: a área da medicina laboratorial com a área da computação. Para facilitar a comunicação com a equipe local, percebeu-se que seria importante a compreensão de conceitos teóricos básicos sobre o trabalho que é realizado no laboratório. Por esse motivo foi conduzido um breve estudo sobre a biologia molecular envolvida nos processos. O material de base foram livros e artigos científicos, porém a colaboração da equipe do laboratório, sanando eventuais dúvidas, foi muito importante.

Em seguida foi preciso mapear os processos realizados no laboratório para o detalhamento final do sistema. Para tal foi necessário um envolvimento com a equipe local e uma imersão na rotina de trabalho para compreensão do funcionamento do sistema interno.

Dentre as metodologias de pesquisa disponíveis, utilizou-se uma que estimula o envolvimento do pesquisador com o ambiente de pesquisa e com o problema a ser estudado. Nesse caso foi adotada a pesquisa participante.

Na observação participante, o observador não é apenas um espectador do fato que está sendo estudado, ele se coloca na posição e ao nível dos outros elementos humanos que compõem o fenômeno a ser observado. Se o pesquisador está empenhado em estudar as aspirações, interesses ou rotina de trabalho de um grupo de operários, na forma de observação participante, ele terá de se inserir nesse grupo de operários como se fosse um deles. [Richardson 1999]

A última etapa foi feita a confecção de um sistema utilizando o framework gratuito Ruby on Rails. Diversos protótipos foram concebidos testando algumas diferentes abordagens para construção e bibliotecas do próprio framework. Optou-se então pela construção de um sistema modular, de modo a ser facilmente expandido e atualizado [Denizet 2015]. Por fim, com intuito de garantir que o produto final fosse robusto e confiável, foi adotado o desenvolvimento guiado por testes. 


\section{O Processo de Tipificação do HLA-UERJ}

Atualmente, o laboratório ocupa o Pavilhão José Roberto Feresin Moraes, localizado na Policlínica Piquet Carneiro. Possui uma equipe com cerca de 25 colaboradores, entre servidores, prestadores de serviço, pesquisadores e alunos de pós-graduação, voltados para a realização de exames de compatibilidade na área de transplante de órgãos sólidos e células-tronco hematopoéticas, exames moleculares referentes às hepatites virais - hepatite $\mathrm{B}$ e hepatite $\mathrm{C}$ - e criopreservação de células-tronco hematopoéticas [HLA-UERJ 2018].

As atividades atuais estão distribuídas entre a realização de exames laboratoriais, a participação em campanhas para cadastramento de doadores voluntários de medula óssea e a oferta de cursos de formação e aperfeiçoamento, além da participação em importantes projetos de pesquisa nestas áreas [HLA-UERJ 2018].

O processo começa com recebimento das amostras, onde existe uma etapa administrativa de verificação de todo o material recebido. Uma parte dessa verificação consiste em etiquetar os tubos das amostras para fácil identificação posterior. Nessa etapa ocorre também um processo de cadastro interno das amostras (etapas 1 e 2 da Figura 1).

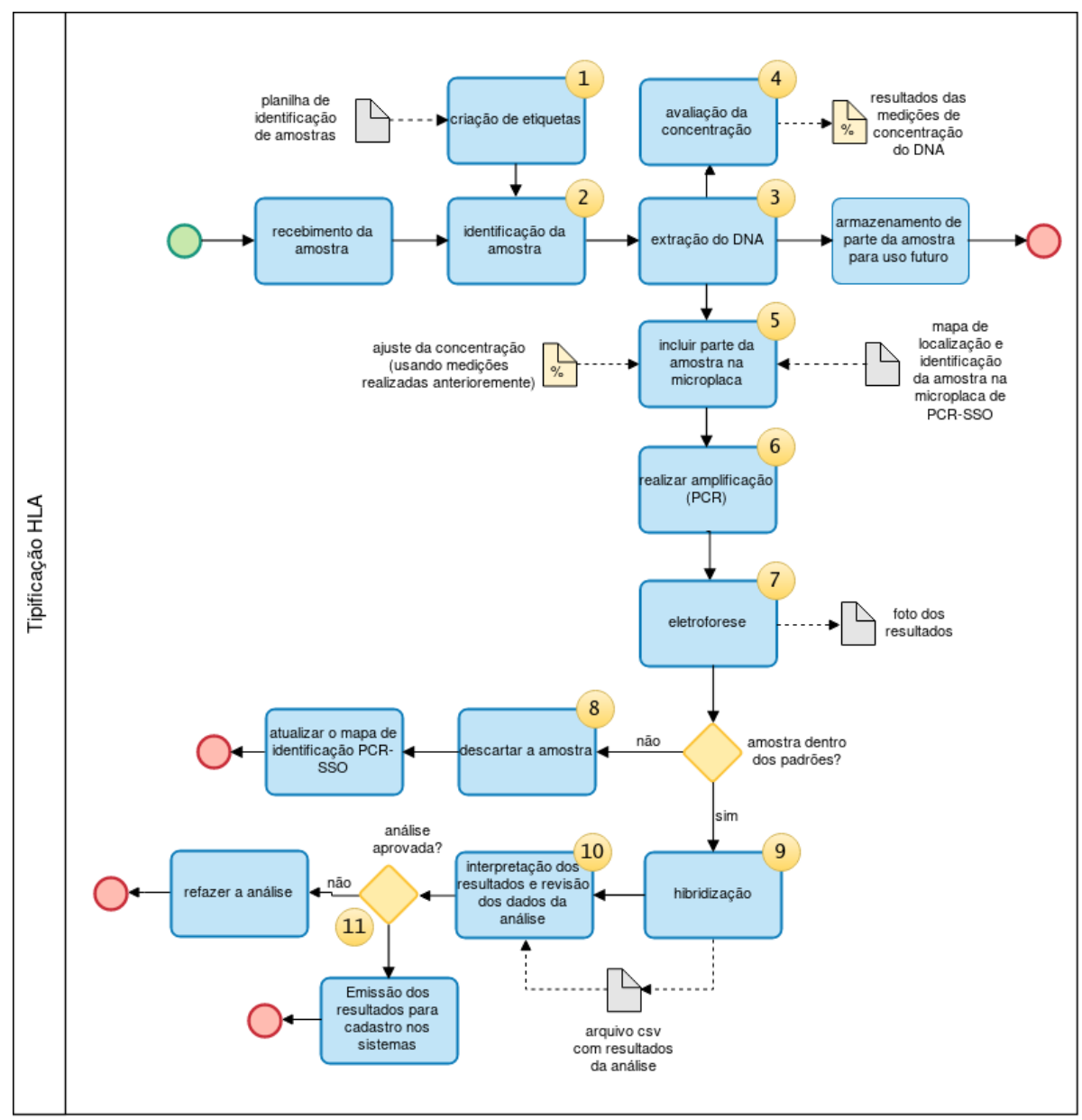

Figura 1. Fluxo do processo de tipificação HLA realizado no HLA-UERJ

A primeira etapa do processamento da amostra consiste na separação das células que possuem DNA dos demais componentes presentes, e posterior extração do DNA do 
núcleo da célula. Para finalizar, é preciso mensurar a concentração de DNA em cada amostra. Essa informação é útil para realizar cálculos de ajuste de concentração em processos futuros. Uma parte do produto dessa manipulação é separado para dar continuidade no processo e o restante é armazenado em câmaras frigoríficas para uso futuro (etapas 3 e 4).

Em seguida segue-se para um processo de amplificação do DNA extraído através da técnica PCR-SSO [Wordsworth 1991] (etapa 6). Porém antes é preciso preparar as amostras para o procedimento e isto é feito transferindo-as para uma microplaca com 96 poços (etapa 5). É preciso identificar apropriadamente o conteúdo de cada poço, relacionando-o com a amostra colocada nele. Isso é feito preenchendo um formulário próprio. Nesse mapa, cada espaço referente a um poço é preenchido com o número que remete ao doador e o tipo de exame que será realizado. Também são incluídos reagentes importantes para a etapa seguinte e são feitos ajustes que levam em consideração dados de concentração de DNA obtidos anteriormente.

Para garantir que houve êxito no processo anterior é utilizada a técnica denominada "eletroforese em gel". O resultado é uma imagem que o técnico utiliza como base para avaliação de quais amostras estão dentro dos padrões (etapa 7). As amostras reprovadas serão descartadas e o formulário é atualizado (etapa 8).

A próxima etapa consiste na hibridização do DNA com Oligonucleotídeos de Sequência Específica (SSO) (etapa 9). Nesse momento a metodologia a ser utilizada dependerá do tipo de análise que foi solicitada - média ou alta resolução. Para essa análise é utilizado um equipamento denominado citômetro de fluxo da empresa Luminex ${ }^{\circledR}$. O computador acoplado ao equipamento possui um software próprio que permite a configuração da máquina de acordo com a análise a ser realizada. Por fim são realizadas interpretações dos resultados (etapa 10) e os mesmos são enviados para cadastro no REDOME (registro nacional dos doadores de médula óssea) ou para o médico requisitante (etapa 11).

\section{Sistemas Informatizados Laboratoriais}

A crescente evolução da tecnologia está impactando de forma drástica as mais diversas áreas da sociedade e, como não podia deixar de ser, a área da saúde também está passando por grandes reestruturações para se adaptar a essa nova realidade. A pressão do mercado por excelência e maior eficiência nos processos para redução de custos, também está atingindo os laboratórios clínicos, e isso está levando a busca por uma automatização de processos.

A primeira automação laboratorial documentada ocorreu no Japão no início da década de 80. Utilizando a tecnologia disponível na época foram realizadas diversas modificações em equipamentos existentes para adequar as necessidades locais. Foram adaptadas esteiras rolantes para carregar as amostras até estações de trabalho analíticas, onde então eram manipuladas por braços robóticos para realização de tarefas mais complexas. Todas as estações podiam operar sem a intervenção humana e o processo inteiro era controlado e monitorado por computadores. Esse tipo de automação ficou conhecido como TLA (do inglês Total Automation System) [Boyd 2002].

Apesar das vantagens que um modelo TLA apresenta, o alto custo para implementação desse tipo de tecnologia tornou-a pouco atraente para laboratórios de 
médio/pequeno porte. Para poder disponibilizar a automatização para todos os laboratórios, os vendedores desses equipamentos optaram por desmembrar o sistema completo em pedaços, assim produzindo pequenos módulos especialistas. Hoje em dia praticamente todos os laboratórios existentes possuem algum grau de automação.

Uma grande questão surgiu dessa separação em módulos: como gerenciar o controle do processo como um todo? No modelo completo, o TLA, fazia parte do projeto do laboratório um ponto de controle central de todos os processos. Nessa automatização parcial, cada módulo tem o seu próprio controle e disponibiliza os resultados somente do que é responsável, sem integração com o resto do laboratório.

A demanda por uma solução para essa questão, aliada ao crescente volume de informações (gerada pela facilidade de realizar as análises por causa da modularização de processos), fez com que surgissem sistemas de gerenciamento de informações que tinham o intuito de administrar todo o fluxo de informações de um laboratório, independente de como ele funcionasse. Esse tipo de sistema ficou conhecido como LIMS (do inglês laboratory information management system). Um LIMS eficaz acompanha todo o ciclo de vida das amostras e análises no processo laboratorial, permite integrar instrumentos e gerencia dados do laboratório em si permitindo o controle e a avaliação de informações de maneira rápida e segura.

Um grande obstáculo enfrentando para implementação desse tipo de sistema são as variações existentes no funcionamento dos laboratórios. Embora os processos realizados sejam semelhantes, podem haver alterações devido ao tipo de equipamento adotado, disposição dos mesmos nos recintos, procedimentos utilizados, entre outros fatores, fazendo com que a adoção de um software de controle de processos seja difícil. Se o aplicativo não for flexível, irá gerar a necessidade de realização de alterações em rotinas do laboratório para ajustar-se a ele, o que em muitos casos não é viável.

Um extenso estudo foi conduzido (tendo como base a internet) com intuito de buscar se já existiam sistemas comerciais disponíveis. O objetivo era testá-los para avaliar se estariam aptos a serem utilizados no laboratório HLA-UERJ, tendo como base o fluxo de trabalho atual. A pesquisa revelou que já existem algumas soluções comerciais (pagas) para gerenciamento de processos laboratoriais, porém nenhuma possuía uma versão demo para avaliação de suas características, impossibilitando um estudo detalhado das funções disponíveis e se os mesmos se adequariam a rotina do laboratório HLA-UERJ.

\section{Sistema de Gerenciamento Laboratorial para o Processo de Tipificação HLA}

A partir do mapeamento apresentado na Seção 3 foi criado um sistema de gerenciamento laboratorial para controle dos processos de tipificação HLA. A aplicação permite um controle centralizado sobre o processo de tipificação HLA do laboratório HLA-UERJ e conta com um grande número de funcionalidades. Dentre as diversas disponíveis, estão presentes a possibilidade de criar usuários e atribuir controle de acesso (administrador ou não), criar análises, incluir amostras, cadastrar doadores e realizar o cadastro de hemocentros e/ ou médicos (solicitantes das análises).

Como o laboratório realiza outros serviços (não considerados nesse primeiro momento), e comumente agrega novas funcionalidades, uma outra característica identificada 
como importante e implementada, foi a possibilidade de expansão do sistema de forma fácil e rápida sem que fosse preciso uma grande reformulação de toda a programação. Para conseguir obter essa característica utilizou-se um conceito de engenharia de software denominado modularização, conforme já descrito anteriormente.

Outro aspecto importante que foi identificado, foi a necessidade de utilizar a aplicação em dispositivos móveis (como tablets, por exemplo), uma vez que em alguns laboratórios há limitação de espaço e/ou o uso de computadores e notebooks é pouco prática. Dessa forma, a interface para o LIMS implementado teve que ser preparada para se adaptar tanto para computadores tradicionais, como também para dispositivos móveis.

O sistema foi desenvolvido com um módulo central, que é um simples repositório de submódulos. Dessa forma basta que sejam seguidos um certo conjunto de regras para criação de novos módulos, que eles se integrarão facilmente sem alterar a dinâmica do que já está em uso.

Soluções computacionais para criação de sistemas complexos como o proposto, requerem a utilização de uma ampla gama de ferramentas para garantir que o produto final não só atenda aos requisitos necessários, como também seja facilmente atualizável e permita modificações quando necessário.

Dentre as muitas opções disponíveis para o desenvolvimento, optou-se por utilizar o framework Ruby on Rails e metodologias como modularização e desenvolvimento guiado por testes, com intuito de deixar o sistema completo e robusto.

\subsection{A linguagem Ruby e o framework Rails}

Ruby é uma linguagem open source, interpretada e orientada a objetos. Uma importante característica é que a linguagem possui um gerenciador de pacotes bastante robusto, flexível e eficiente denominado RubyGems. As assim chamadas gems são como bibliotecas reutilizáveis de código Ruby, que possuem algum tipo específico de funcionalidade, assim como qualquer outro arquivo relacionado [Ruby Community sd].

Essa organização em Gems ajuda a resolver alguns problemas bem comuns no desenvolvimento de aplicações extensas, pois fornece uma estrutura padrão para distribuição das bibliotecas e ferramentas Ruby, e também facilita o gerenciamento de dependências.

O Ruby on Rails (RoR) é uma gem que fornece um framework livre de desenvolvimento Web escrito na linguagem de programação Ruby. A estrutura inicial foi desenvolvida por David Heinemeier Hansson e posteriormente foi ampliada pelo esforço conjunto de uma equipe de vários contribuintes. O RoR permite que sejam desenvolvidos aplicativos Web de forma rápida, minimizando as etapas, o tempo e o código envolvido na programação.

A segurança do RoR também é uma ponto forte, sem que seja necessário que o desenvolvedor faça nenhuma configuração. Alguns casos típicos de falhas já exploradas são tratadas por padrão, como sql-injection, cross-site scription, session hijacking, entre outros.

A partir da versão 3.1 do Rails foi criado um conceito para facilitar a extensão de uma aplicação chamado Rails Engine. Esse conceito é extensamente utilizado no presente trabalho e consiste em uma mini aplicação Rails cujas funcionalidades estão isoladas e 
podem ser reaproveitadas em qualquer outra aplicação Rails de uma forma estruturada. Uma vez finalizado o desenvolvimento, é possível exportar essas aplicações na forma de gems.

\subsection{Modularidade}

O conceito de modularidade é uma especialização de um importante princípio da engenharia de software, que é o da Separação de Conceitos - SoC (do inglês Separation of Concerns). O princípio da $\mathrm{SoC}$ é um conceito que sugere que qualquer problema complexo pode ser resolvido de forma mais eficiente se forem identificadas a priori os diferentes tipos de conceitos envolvidos, e então usar esse conhecimento para subdividi-lo em pedaços que possam ser resolvidos e/ ou otimizados independentemente.

A utilização do princípio da separação de conceitos traz consigo inúmeras vantagens. O particionamento do software torna a manutenção mais fácil pois permite com que seja mais simples garantir a falta de duplicação e singularidade de propósito das partes individuais. Dessa forma o sistema também tende a ser mais estável, subproduto da facilidade de manutenção. A dissociação das funcionalidades leva a criação de componentes especialistas, o que leva a componentes que são mais facilmente reutilizáveis em outros sistemas, ou até mesmo em outros contextos dentro do mesmo sistema [Laplante 2017].

Em um ambiente laboratorial, a utilização desse conceito permite a criação de aplicativos flexíveis que possam se adaptar a realidade dos procedimentos utilizados naquele local (as alterações necessárias serão modulares e não globais), bem como a inclusão de novas funcionalidades (novos módulos) caso o laboratório comece a realizar outros tipos de exames.

\subsection{Desenvolvimento Guiado por Testes}

De forma resumida, podemos dizer que o desenvolvimento guiado por teste (TDD) (do inglês Test-driven Development) é uma técnica de desenvolvimento de software que tem como premissa base a criação de testes antes do código principal, i.e., antes de qualquer mudança no código de produção o programador deve ter escrito testes falhos. O passo seguinte consiste na escrita do mínimo de código funcional para que o teste seja atendido e no fim realizar uma etapa de refatoração, com intuito de eliminar qualquer duplicata no código [Myers 2019].

Tradicionalmente, os testes unitários eram executados após o desenvolvimento. Essa tarefa poderia levar desde alguns minutos até mesmo meses. Os testes poderiam ser escritos pelo próprio programador ou por um profissional designado somente para esse fim. Com o TDD, o programador escreve os testes antes do código que será testado. Como resultado, o programador pode executar os testes assim que eles forem escritos [Myers 2019].

A técnica já provou ser bastante efetiva quando aplicada em empresas desenvolvedoras de softwares comerciais. Na prática o TDD faz com os desenvolvedores reflitam melhor em como o sistema deve ser organizado [Karac and Turhan 2018].

Para o desenvolvimento de sistemas complexos, onde existem dependências entre as partes, a atualização de uma funcionalidade pode vir a criar problemas em outras partes da aplicação. Na aplicação desenvolvida foram escritos mais de 100 testes de modo a garantir que mudanças futuras não afetem o funcionamento dos módulos já feitos. 


\subsection{Descritivo dos Módulos da Aplicação}

Após extensa análise do fluxo de informações que ocorre no laboratório, e com base na ideia de modularização, optou-se por subdividir a aplicação em 4 partes (Figura 2).

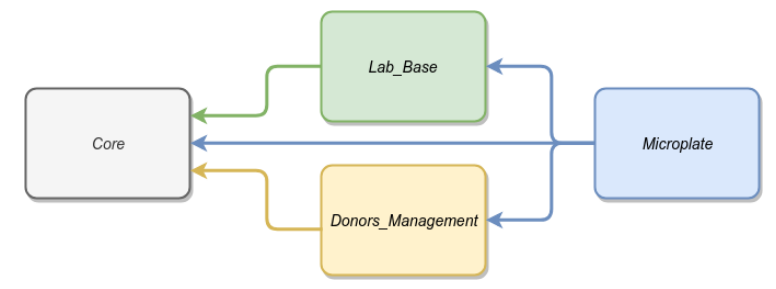

Figura 2. Módulos da aplicação (as setas representam as dependências)

O módulo nomeado Core é o responsável pela parte de autenticação e autorização de usuários. Como o sistema precisa lidar com informações sigilosas, como dados de pessoas e exames, é preciso restringir o acesso de pessoas não autorizadas. Esse módulo exerce justamente essa função, só permitindo a entrada de pessoas previamente aprovadas e com um login e senha cadastrados. Para a aplicação, foram definidos dois tipos distintos de usuários: comum e administrador. $\mathrm{O}$ usuário administrador tem acesso a todas as funcionalidades do sistema, enquanto o usuário comum poderá somente acessar dados de análises.

A base da interface gráfica também é toda fornecida por este módulo. Dessa forma os demais só precisam implementar suas funcionalidades e copiar os padrões de interface disponíveis nesse módulo. Outra importante característica é que toda a interface foi desenvolvida de forma que seja possível acessá-la tanto de um computador, quando de um dispositivo móvel, ou seja, os diversos componentes da aplicação (por exemplo menus e tabelas), ajustam-se automaticamente de acordo com o tamanho da tela.

Toda rotina laboratorial foi implementada no módulo nomeado Lab_Base. Neste são gerenciadas a criação de tipos de análises e suas etapas e também todo o caminho percorrido pelas amostras ao longo das diversas etapas no laboratório.

Diversos recursos foram implementados com intuito de facilitar a visualização e organização das muitas análises que podem estar ocorrendo me paralelo, como por exemplo um código de cores para representar o andamento das análises e suas subetapas, a possibilidade de reordenar por nome, código e data de criação, filtros por tipo de análises, entre outros recursos. Como exemplo, a Figura 3 apresenta a visualização de tela que mostra todas as análises não arquivadas. Nesta é possível ver o código de cores adotado para representar o estado da análise. O cinza representa as análises criadas no sistema, porém não inicializadas, o amarelo, análises em andamento, o vermelho é utilizado para as que foram canceladas e, por fim, o verde indica as análises concluídas. A legenda encontra-se na barra lateral.

Como o gerenciamento dos doadores é uma tarefa bastante extensa, e independe do fluxo das análises em si, optou-se por criar um módulo separado para este fim. O módulo denominado de Donors_Management provêm ferramentas para o gerenciamento do cadastro de doadores. Com os recursos implementados fica fácil a inclusão e alteração de dados, bem como a busca - tarefa bastante corriqueira no cotidiano do laboratório.

A edição pode ser feita de duas formas. Em lote, onde o usuário seleciona uma 


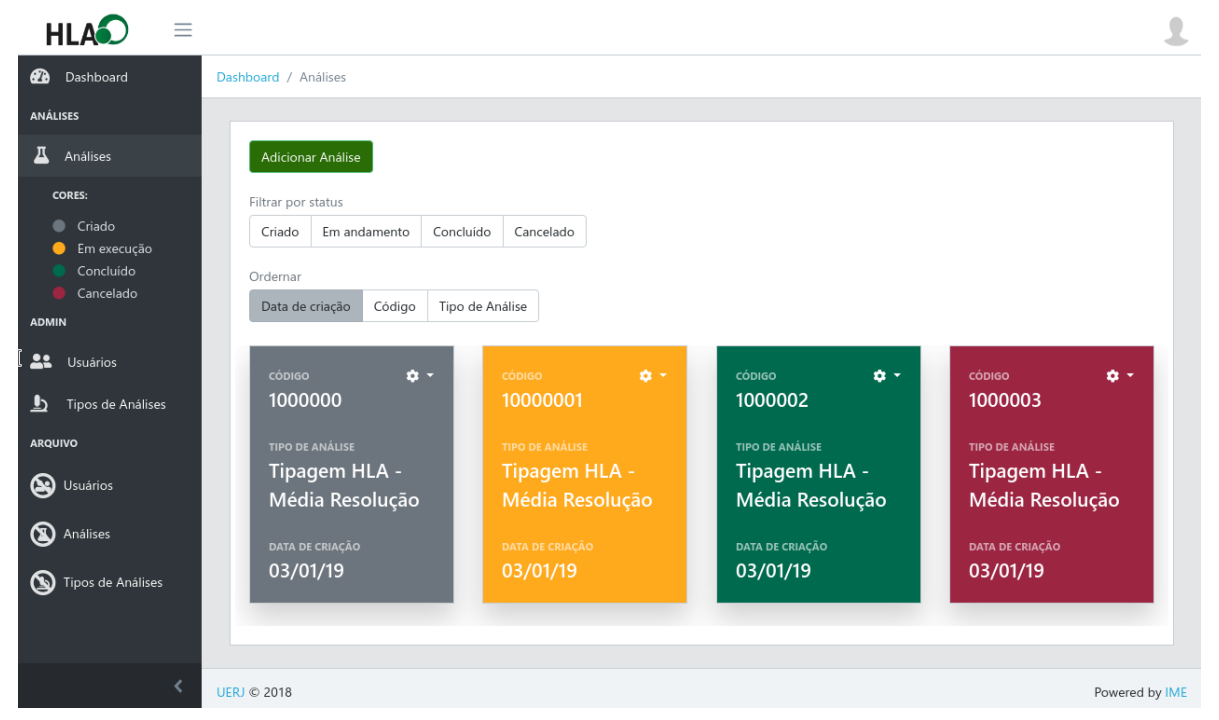

Figura 3. Tela de gerenciamento das análises

lista criada previamente com os nomes dos doadores que deseja editar ou, se a mudança for pontual, basta clicar na célula que pretende corrigir na tabela com as informações.

Uma etapa bastante importante dentro da análise, consiste na disposição das amostras em microplacas para realização de diversos procedimentos. Toda a manipulação das informações necessárias para esse fim, ficaram separadas em um módulo nomeado $\mathrm{Mi}$ croplate. Este depende de informações geradas em todos os outros módulos, visto que as amostras são de doadores (cadastrados no módulo Donors_Management) e a microplaca em si é parte de uma análise (criada no módulo Lab_Base). De modo a deixar esse módulo flexível, foi incluída um ambiente onde é possível criar tipos de microplacas diferentes da do padrão utilizado pelo laboratório (com 96 poços, apresentada na Figura 4). Desse modo é possível também criar tipos para outros exames que necessitem de outras placas disponíveis no mercado, por exemplo com 6, 12, 24, 48, 384 ou 1536 [Eppendorf International sd][Sarstedt sd], e até mesmo placas fora do padrão se necessário.

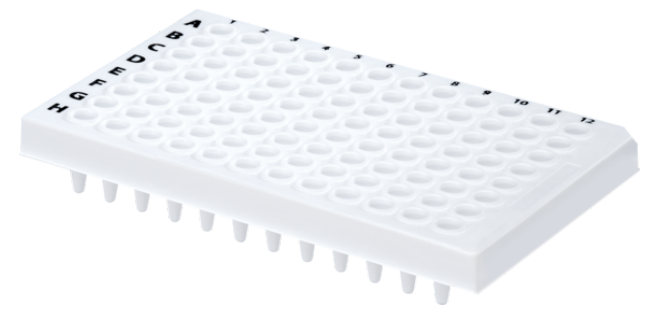

Figura 4. Exemplo de microplaca utilizada no processo

A Figura 5 apresenta a tela de organização da microplaca. Ela contêm uma representação da mesma em forma de tabela, com a marcação de linhas e colunas de forma idêntica a placa real, e permite que o usuário aloque as amostras e seus respectivos exames em um determinado poço de forma simples e intuitiva. Todas as informações estão organizadas em menus e os doadores/exames em cada poço podem ser alocados facilmente simplesmente arrastando as informações de um poço para o outro. 


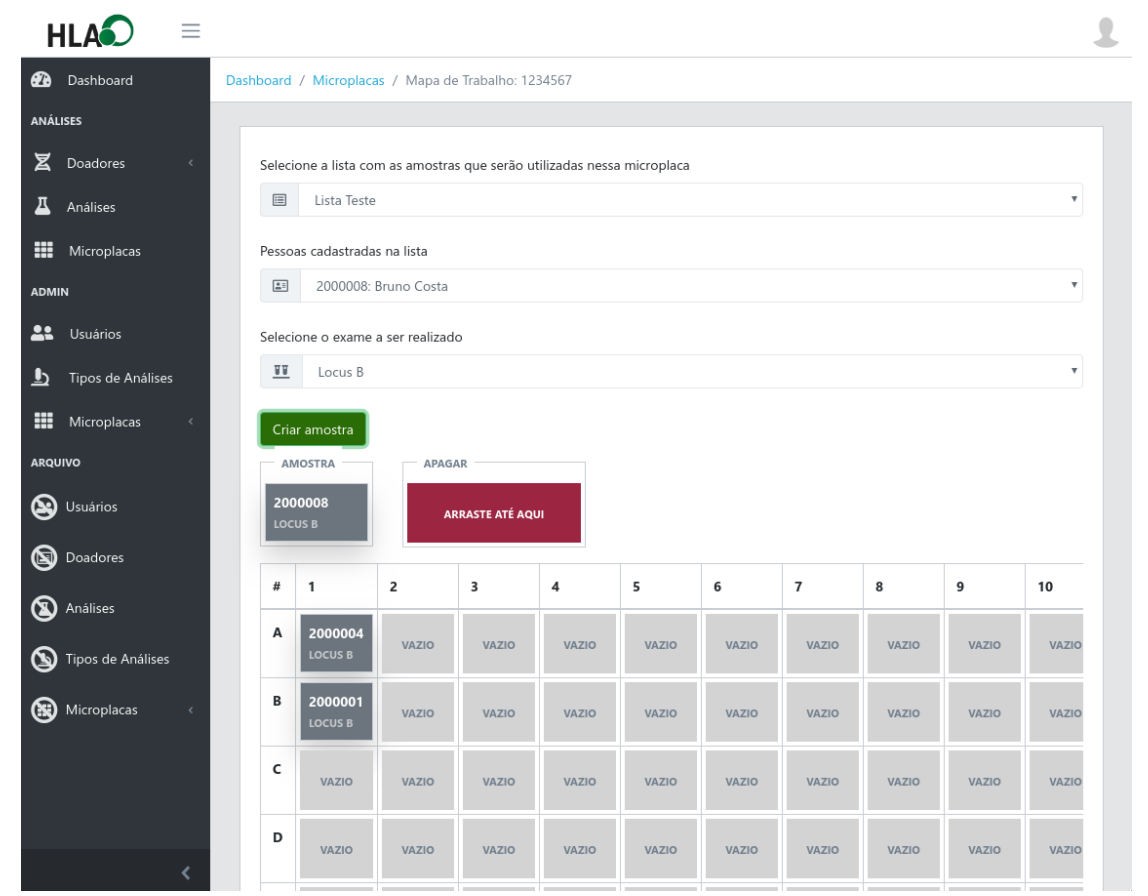

Figura 5. Tela de cadastro de análises na microplaca

Como nenhuma parte do sistema fica aberta para visualização sem autenticação (somente as pessoas cadastradas poderão interagir com a aplicação), todos os módulos dependem do módulo Core (cor cinza na Figura 2), que é o gerenciador dos usuários.

Um aspecto importante é que a aplicação foi configurada de modo que não seja possível apagar completamente registros importantes. Essa abordagem tem como intenção evitar que informações sejam perdidas acidentalmente e para manter um registro de todas as operações realizadas. O usuário com acesso de administrador tem acesso a uma área especial da aplicação denominada "Arquivo" onde poderá visualizar todos os registros que foram arquivados e recuperá-los se assim desejar.

Com a combinação de todos os módulos, é possível acompanhar todo o processo de tipificação HLA e obter diversas informações rapidamente, como por exemplo o andamento das análises, quais foram canceladas ou tiveram algum tipo de problema, obter dados dos doadores, entre outras.

\section{Conclusões}

A tipificação HLA é o principal exame para identificar a compatibilidade entre doadores/receptores de orgãos, diminuindo consideravelmente a chance de rejeição.

O presente trabalho mapeou todos as etapas associadas ao processo de tipificação HLA desenvolvido no laboratório HLA-UERJ e desenvolveu um sistema informatizado de gestão laboratorial (LIMS) customizável que controla todas das atividades envolvidas nessa análise. O tamanho da tarefa exigiu com que fossem utilizadas algumas técnicas computacionais para garantir que o sistema não só atendesse aos requisitos imediatos do laboratório, mas pudesse ser de fácil manutenção, atualização e expansão.

A aplicação mapeia toda a vida de uma amostra ao longo das diversas etapas de 
uma análise dentro de um laboratório de tipificação HLA, de maneira que poderá ser utilizado, não somente pelo HLA UERJ, mas por qualquer laboratório que realize este tipo de exame.

A disponibilidade da aplicação em módulos e a possibilidade de criação de tipos de análise e microplacas, por exemplo, fazem com que seja possível utilizar a aplicação em outros tipos de laboratórios (além dos que realizam tipificação HLA), pois permite fácil adaptação para outros processos.

Por fim, como trabalho futuro, pretende-se desenvolver módulos para obter dados estatísticos das análises realizadas e processos pendentes, o que permitiria uma avaliação do funcionamento do laboratório e, consequentemente, um aprimoramento de suas atividades.

\section{Referências}

Abbas, A. K. and Lichtman, A. H. (2004). Basic Immunology. Functions and Disorders of the Immune System. Elsevier, 2 edition.

Boyd, J. (2002). Robotic laboratory automation. Science, 295(5554):517-518.

Campana, G. A., Oplustil, C. P., and de Faro, L. B. (2011). Tendências em medicina laboratorial. Jornal Brasileiro de Patologia e Medicina Laboratorial, 47(4):399-408.

Denizet, T. (2015). The Complete Guide to Modular Rails Application. Thibault Denizet, 9 edition.

Eppendorf International (s.d.). Laboratory equipment, supplies \& services. https: //www. eppendorf.com/.

HLA-UERJ (2018). HLA - laboratório de histocompatibilidade e criopreservação - UERJ. https://www.hla.uerj.br/site.

Karac, I. and Turhan, B. (2018). What do we (really) know about test-driven development? IEEE Software, 35(4):81-85.

Laplante, P. (2017). What Every Engineer Should Know about Software Engineering. What Every Engineer Should Know, a Series. Taylor \& Francis Group.

Myers, R. C. (2019). Essential Test-Driven Development. Addison-Wesley Professional.

Opelz, G. and Döhler, B. (2007). Effect of human leukocyte antigen compatibility on kidney graft survival: Comparative analysis of two decades. Transplantation, 84(2):137143.

Paszko, C. and Turner, E. (2001). Laboratory Information Management Systems, Second Edition,. CRC Press.

Richardson, R. (1999). Pesquisa social: métodos e técnicas. Atlas.

Ruby Community (s.d.). Ruby, a programmer's best friend. https://www . ruby-lang.org/.

Sarstedt (s.d.). Sarstedt. https : //www. sarstedt.com/.

Wordsworth, P. (1991). PCR-SSO typing in HLA-disease association studies. International Journal of Immunogenetics, 18(1-2):139-146. 